\author{
H. Coignard-Biehler \\ A. Isakov \\ J. Stephenson
}

\section{Pre-hospital transportation in Western countries for Ebola patients, comparison of guidelines}

Received: 16 December 2014

Accepted: 24 February 2015

Published online: 24 March 2015

(C) The Author(s) 2015. This article is published with open access at Springerlink.com

\section{H. Coignard-Biehler (®)}

SPILF COREB Emergences (Coordination Opérationnelle du Risque Epidemique et Biologique), COREB AP-HP, LabEx IBEID Institut Pasteur, Service des Maladies Infectieuses et Tropicales, SAMU 75, Hôpital Necker-Enfants Malades, Paris, France e-mail: helene.coignard@nck.aphp.fr

\section{A. Isakov}

Department of Emergency Medicine, Emory University School of Medicine, Atlanta, GA, USA

e-mail: aisakov@emory.edu

\section{J. Stephenson}

National Ambulance Resilience Unit (NARU), Police National CBRN Centre, Ryton on Dunsmore, Coventry CV8 3EN, UK e-mail: john.stephenson@wmas.nhs.uk

\section{Introduction}

The emergence of the Ebola virus disease (EVD) outbreak in West Africa threatens regional and global public health security. This epidemic, first announced in March 2014 in Guinea Conakry, has grown dramatically since June 2014 with an extension into Liberia and Sierra Leone. Nigeria, Mali, and Democratic Republic of the Congo were also transiently affected. It was declared to be a public health emergency of international concern by the World Health Organization (WHO) on 8 August 2014. On 21 January 2015 , a cumulative total of more than 21,800 cases was reported by the WHO [1], with a case fatality rate (CFR) of between 57 and $59 \%$ among hospitalized patients. A total of 828 healthcare workers (HCWs) have been infected with the Ebola virus since the beginning of the epidemic, with a CFR of $60 \%$. Some Western countries have also reported imported cases: six patients in the USA, Spain and UK, including one death (CFR of $16.7 \%$ ). Direct contact with infected bodily fluidsusually feces, vomit, or blood-is necessary for transmission. Once the Ebola virus is suspected, based on national versions of WHO's case definition recommendations [2], specific laboratory tests can confirm or disprove diagnoses in a few hours, but for this, the patient has to be transported to a specialized center with specific management conditions [3]. In this article, the authors compared procedures for the transport of Ebola patients in their respective countries (USA, UK, and France) to identify common principles.

\section{National guidelines for transportation of patients with suspected or known EVD}

Although the epidemic is largely confined to West Africa, most Western countries where there is a possible risk of imported EVD have developed guidelines and procedures for the transport of confirmed or suspected cases of EVD. Specific recommendations are informed by risk for exposure to EVD. In the USA, the Interagency Board for Equipment Standardization and Interoperability describes a spectrum of risks based on patient symptomology and application of personnel protective equipment (PPE) to accommodate the level of risk [4]. This spectrum of risks is also acknowledged in the US Center for Disease Control's guidance [5] for emergency department and emergency medical services (EMS) evaluation and management of patients with possible EVD. In the UK, the Advisory Committee on Dangerous Pathogens (ACDP) advises a stratified risk approach based on simple 
symptomatology [6] that guides the healthcare professionals to the appropriate level of personal protective equipment. In France, transportation conditions were described in a document written by emergency specialists [7], being currently updated by infectious disease and hygiene specialists.

Patient circumstances (possible or confirmed cases, severity of illness)

The clinical features of EVD are increasingly well described in the literature [8-10]. Symptoms of the patients to transport vary, and precautions must take into account the patient's condition and the risk they pose to transporting clinicians. To simplify the risk assessment and organization of transportation that follows (presented in Table 1), two sorts of patients have been identified: a possible Ebola patient with few symptoms apart from fever can be considered to have a low risk of transmission (case 1 in Table 1), and a patient with symptoms of profound diarrhea and vomiting, bruising, and bleeding or one with confirmed EVD several days into the course of their illness poses a substantial risk of transmission to transporting clinicians (case 2 in Table 1). An appropriate care plan should be developed for each patient journey, including the need for intravenous access [11], according to the clinical data available.

Personnel (team composition, training)

\section{Composition of transfer unit/team}

Composition of the transport team varies by country. In the US, personnel should at a minimum be capable of safe carriage of nonambulatory patients and providing basic life support measures. Advanced life-support skills, such as fluid and electrolyte replacement, and management of hypotension and cardiac dysrhythmias may be warranted based on the patient's clinical condition and availability of staff with the requisite skill set. Health systems in the USA identified as capable of managing a patient through a full course of EVD have developed partnerships with local EMS agencies with the requisite competencies. In the UK, only high-risk patients need to be transported with medical staff (with two clinicians and a transfer officer). In France, transportation conditions are managed by the Service d'Aide Médicale d'Urgence (SAMU), which is the prehospital emergency medical system, in each department of France. Overall choices in the SAMU have evolved from a prehospital team that could have no medics to a highly skilled team capable of medical transfers regardless of the clinical status of the patient. HCWs with underlying conditions such as pregnancy, asthma, and claustrophobia are excluded.

Adequate training of HCWs is essential, with the following recommended requirements: prior to transport of a possible or infected Ebola patient, all healthcare workers must receive repeated training and have demonstrated competency in performing all required infection-control practices and procedures; repeated practice in donning/doffing of proper PPE is indispensable for the development and demonstration of competence; the overall safe management of Ebola patients is best executed with observation/supervision of the critical actions required of the transport team.

Equipment (PPE, vehicle)

\section{PPE for HCWs and patients}

Personal protective equipment should reflect the condition of the patient, work environment, operational objectives, and competencies of the transport team to apply it. According to the clinical status and national choices, several suits can be used. The minimum PPE, which can be designated as "low grade," includes at a minimum gloves to protect the hands, a gown or coverall to protect the clothing, and a mask/face shield to protect the mucous membranes. "High-grade" PPE involves a robust visor in addition to a fluid repellent suit, boots, double gloves, face mask, and head protection. There are also positivepressure suits (PPS), which have the advantage of excellent protection, superior comfort and vision. These very expansive PPSs are available in Germany, for example, but reserved to specific circumstances in specialized treatment centers [11]. Whatever the PPE chosen, the staff needs to be confident and competent in wearing it and its safe removal. Training as well as practicing each step of the procedure is a must, with the external control of a supervisor. The patient is also most often dressed in a single-use outfit and mask. Supplementary isolation inside a slipcover or caisson has been adopted by some for patients regarded as high risk for transmission of the virus.

\section{Vehicle equipment}

In the US, standard ambulance equipment is used, but shielded with impervious barrier drapes for symptomatic patients. Sometimes another vehicle can escort the dedicated vehicle to assure logistic support and external supervision. In the UK, for a low-risk patient a standard ambulance is used, but for high-risk patients specialist HART staff will use a stripped out ambulance with minimal equipment, and taped up cupboards are used to facilitate cleaning and reduce the amount of equipment that may need to be destroyed. In France, the SAMU regions are autonomous and have different plans: mostly, a stripped out vehicle has been dedicated, and minimal equipment can be added in each case. 


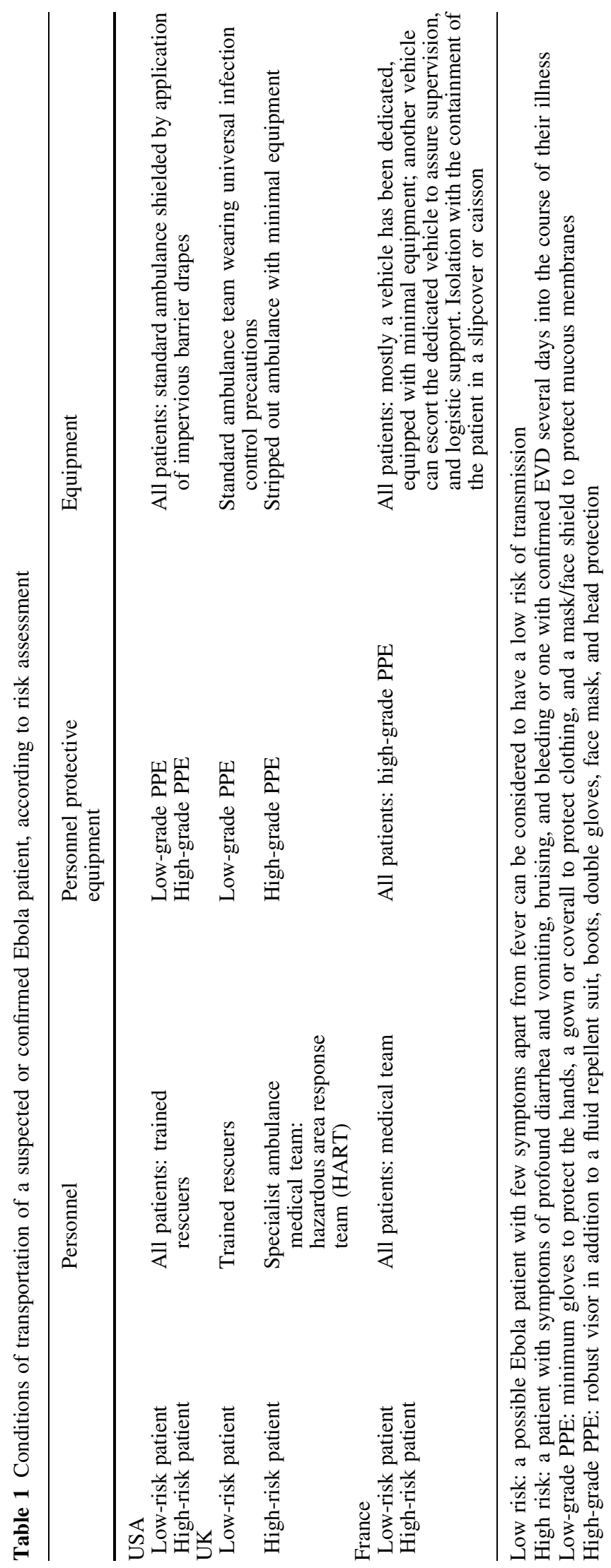


Donning and cleaning procedures

The staff involved in the patient episode need to be trained, equipped, and practiced in wearing and removing the PPE safely. In the USA, transporting teams have facilitated decontamination and disinfection by isolating the driver compartment from the patient compartment and use of impervious drapes. In our countries, the ambulance staff who transport the patient will perform the decontamination and disinfection of the vehicle cabin using hypochlorite solution or a registered disinfectant. In France, a vaporization of hydrogen peroxide or another virucidial gas is usually applied secondarily. Moreover, in the UK, the vehicle is subsequently taken for a specialist deep cleaning prior to reuse.

\section{Perspectives}

Public health measures such as early isolation and infection control are necessary from the earliest suspicion of EVD, and the transportation of patients includes some risk.
In West Africa, Ebola patient transportation has been a source of secondary cases because of the absence of a robust "prehospital" health system, leading to transportation of patients mostly by their families, without implementation of infection control measures. However, safe transportation of Ebola patients by non-governmental organizations as "Doctors without borders" are organized. Guidelines of Western countries do not seem to be relevant in Africa, because of the healthcare worker/patient ratio, expensive costs of safety measures (number of vehicles and protective equipment for personnel), and the absence of prehospital organization. In the US, countless numbers of possible patients have been transported and evaluated, none of whom were confirmed to have the disease. Ten patients with confirmed EVD have been transported by EMS. In France, up to now, 22 possible patients have been transported in accordance with the guidelines described here, none of whom were confirmed, and 2 EVD patients were transported in a medical evacuation.

Development of point-of-care tests to quickly disprove the diagnosis of infection with Ebola virus [12] could strongly reduce the number of specialized and complicated transports and thus the risk of secondary infection.

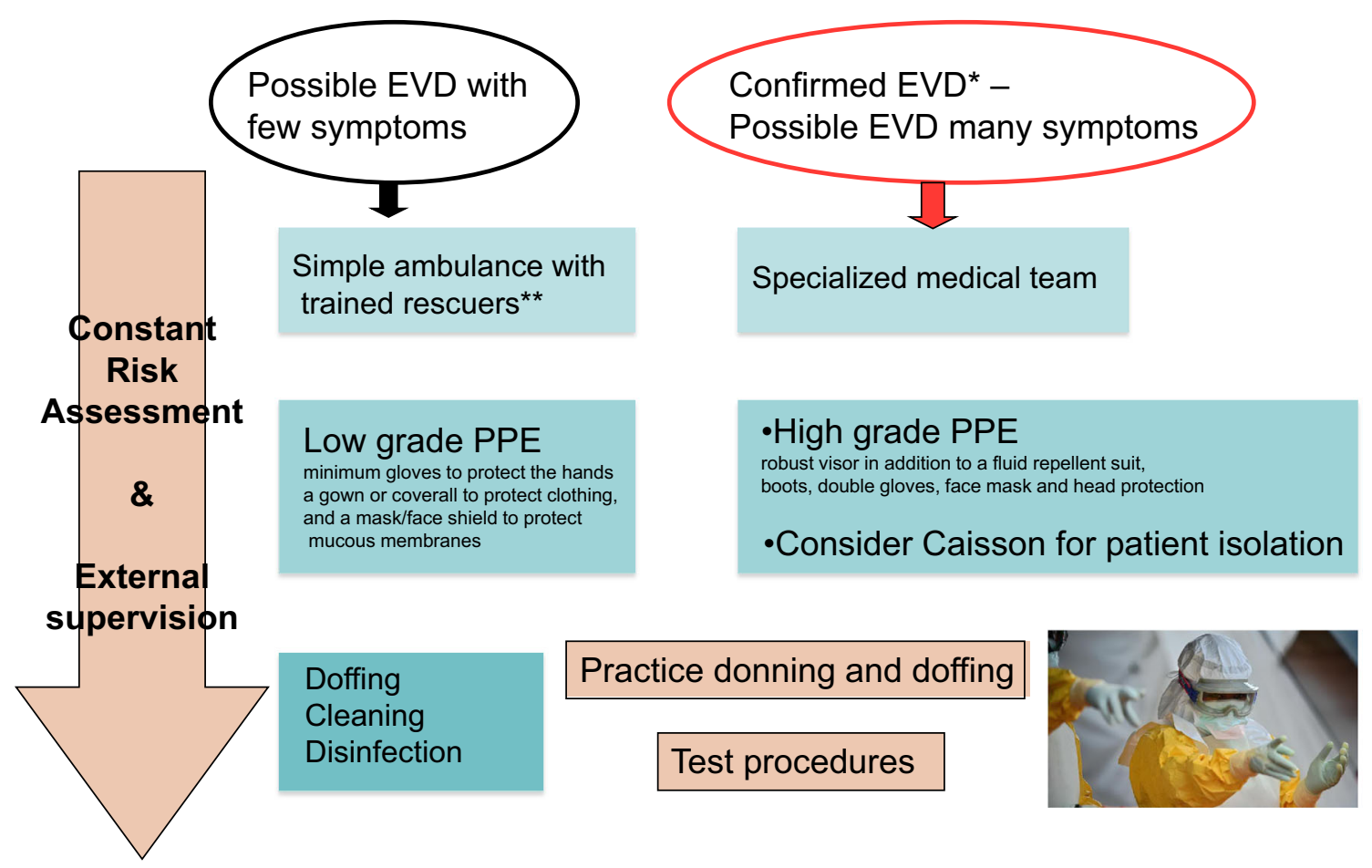

*time of clinical course can be considered

Perspective from the authors

${ }^{* *}$ In France, medical staff is required

Fig. 1 Transportation of Ebola patients 


\section{Conclusion}

Comparison of our three countries' guidelines highlights the importance of key principles that are necessary for a trained team [13] to improve their performance in stress conditions and avoid possible fatal mistakes, including the necessity of detailed procedures concerning doffing and disinfection, as well as risk assessment for each situation, with procedures adapted to local circumstances and the patient's clinical presentation (Fig. 1). This guidance is continuing to evolve to accommodate new data and experience.

Open Access This article is distributed under the terms of the Creative Commons Attribution Noncommercial License which permits any noncommercial use, distribution, and reproduction in any medium, provided the original author(s) and the source are credited.

\section{References}

1. World Health Organization (2015) Ebola response roadmap, situation report. 21-Jan-2015

2. World Health Organization (2014) Case definition recommendations for Ebola or Marburg virus diseases. 08-Aug2014

3. Pasquier P, Ficko C, Merens A, Dubost C (2015) Preparing an ICU room to welcome a critically ill patient with Ebola virus disease. Intensive Care Med 41(1):118-119

4. The Interagency Board for Equipment Standardization and Interoperability (2014) Recommendations on selection and use of personal protective equipment for first responders against Ebola exposure hazards

5. Centers for Disease Control and Prevention (2014) Interim guidance for emergency medical services (EMS) systems and 9-1-1 public safety answering points (PSAPs) for management of patients with known or suspected Ebola virus disease in the United States
6. Advisory Committee on Dangerous Pathogens (2012) Management of hazard group 4 viral haemorrhagic fevers and similar human infectious diseases of high consequences

7. SAMU Urgences de France (SUdF), Société française de Médecine d'Urgences (SFMU) (2014) Procédure de prise en charge des appels pour suspicion de fièvre à virus Ebola (FVE)

8. Yazdan Y, Ramon AJ, Denis M (2014) Treatment of Ebola virus disease. Intensive Care Med 41(1):115-117

9. Lyon GM, Mehta AK, Varkey JB, Brantly K, Plyler L, McElroy AK, Kraft CS, Towner JS, Spiropoulou C, Stroher U, Uyeki TM, Ribner BS (2014) Clinical care of two patients with Ebola virus disease in the United States. N Engl J Med 371(25):2402-2409

10. Isakov A, Jamison A, Miles W, Ribner B (2014) Safe management of patients with serious communicable diseases: recent experience with Ebola virus. Ann Intern Med 161(11):829-830
11. Wichmann D, Schmiedel S, Kluge S (2014) Isolation in patients with Ebola virus disease. Intensive Care Med 41(3):511-513

12. Drain PK (2015) Ebola: lessons learned from HIV and tuberculosis epidemics. Lancet Infect Dis 15(2):146-147

13. Antonelli M, Bonten M, Chastre J, Citerio G, Conti G, Curtis JR, De Backer D, Hedenstierna G, Joannidis M, Macrae D, Mancebo J, Maggiore SM, Mebazaa A, Preiser J-C, Rocco P, Timsit J-F, Wernerman J, Zhang H (2012) Year in review in Intensive Care Medicine 2011. II. Cardiovascular, infections, pneumonia and sepsis, critical care organization and outcome, education, ultrasonography, metabolism and coagulation. Intensive Care Med 38(3):345-358 